\title{
JD23
}

\section{The Leonid Meteor Storms: Historical Significance and Upcoming Opportunities}

\author{
Chairperson and Editor: I. P. Williams
}




\title{
JD23 THE LEONID METEOR STORMS:- HISTORICAL SIGNIFICANCE AND UPCOMING OPPORTUNITIES
}

\author{
I.P.WILLIAMS \\ Astronomy Unit \\ Queen Mary and Westfield College \\ London E1 4 NS \\ $U K$
}

\section{Introduction}

Without doubt, the Leonid stream is the most famous of all the known meteoroid streams. The reason for this is not hard to find, the display of meteors that it produces at times far surpassess anything that any other shower can produce. The showers of 1799,1833 and 1966 all have numerous engravings or photographs recording the splendidness of the displays. The recorded history of the appearances of spectacular Leonid displays dates back for two millenia. Though the associated parent comet, 55/P Tempel-Tuttle, was only discovered in 1861.

This Joint Discussion dealt with three aspects of the Leonid meteor storms. First, a number of contributions deals with the historical aspects, describing the recorded facts regarding both the shower and the comet. Second, the theoretical evolution of the Leonid stream was discussed with the aim of both understanding the past behaviour and predicting the behaviour of the stream in the future, with particular reference to the question of whether the present approach of comet 55P/Tempel-Tuttle herald a spectacular display of the Leonids or not.

Following onto this later consideration are the plans in hand for the observations of the Leonids over the next few years and a number of contributions discussed this aspect.

\section{The Presentations at the Joint Discussion}

The presentation at the meeting fall into two groups, oral and poster. The oral presentations were all contributions invited by the Scientific Organizing Committee. Short summaries of the oral presentations, produced by the contributors, follow this introduction. The poster presentations were submitted by their respective authors and considered by the Scientific Organizing Committe before acceptance.

The titles of the poster papers that were actually displayed at the General Assembly together with their authors follows.

\section{Poster Papers}

3.1. METEOR LUMINOSITY AT $160 \mathrm{KM}$ ALTITUDE FROM TV OBSERVATIONS FOR BRIGHT LEONID METEORS.

Y. Fujiwara, M. Ueda, Y. Shiba, M. Sugimoto, M. Kinoshita, C. Shimoda, T. Nakamura.

\subsection{THE LONG-TERM VARIATION OF THE GEMINIDS METEOR SHOWER.}

K. Izumi.

\subsection{THE LEONID FIREBALL PHOTOGRAPHED IN THE JAPANESE FIREBALL NETWORK IN} 1996.

Y. Shiba, C. Shimoda, T. Marıyama, S. Okumura, M. Tomita, A. Murasawa, K. Ohtsuka. 
3.4. A NEW PEAK OF LEONIDS OBSERVED BY RADIO TECHNIQUES.

K. Suzuki, K. Maegawa, Y. Minagawa.

3.5. THE ORBITS OF FAINT TV LEONIDS METEORS.

S. Suzuki, K. Suzuki, T. Yoshida.

3.6. TV OBSERVATION OF THE 1995 LEONIDS.

M. Ueda, Y. Fujiwara.

3.7. SPACECRAFT DETECTION OF THE LEONID METEOROID STORMS.

H. Yano, T. Takano. 